\section{DE DE GRUYTER} OPEN
Journal of Intercultural Management

Vol. 6, No. 3, September 2014, pp. 197-209

DOI 10.2478/joim-2014-0030

Peter Van Nispen*

Ryerson University Accounting Society, The Netherlands

\title{
The Framework of Culture: a Frame for Work
}

\begin{abstract}
Although culture has been discussed in quite some detail, it remains an elusive concept, whether on content or in terms of consequences. Indeed, culture does not exist in a physical form (although bumping your nose to culture may be a near physical experience) and may be rather considered as a label people use to describe patterns of thinking and acting of a group of people. Many studies of culture start from theory and move to implementation. This paper is based on an opposite approach. Its basis is the experience of 849 MA students with living and working abroad and the effects of culture in reality. In an inductive way this experience results in a mind-map of culture.

The aim of this paper is to present a rather comprehensive perception of culture on the basis of experience; not to give an overview of what culture might be according to the literature. This concept is the initial result of an on-going programme at the R\&D Centre of the Rotterdam University of Applied Sciences. Consecutive steps are briefly mentioned.
\end{abstract}

Key words: culture, students experiences, mind-map of culture.

\section{Data Collection}

\section{Teaching and Papers}

In 2000 the Faculty of Social Sciences and Arts at Maastricht University started the master programme European Public Affairs. Later the master programme Analysing Europe and in 2005 the master programme European Studies were established. The author of this paper was asked as a guest lecturer in these programmes to give an introduction on culture. The last few years only students from the master programme European Studies participated. The outline of the 2013 introductions

*p.nispen@ziggo.nl 
on culture may be found in text box 1. Two major topics were not included in this programme (organisational culture and living and working abroad), but did get attention through the discussions and in the papers by the students.

\section{Textbox 1: Overview of the Introductions on Culture}

- Concept of Culture

- Barriers in Studying Culture

- Definitions (Hofstede, Trompenaars, Vroom, Barker and more)

- Concepts (Van Asperen, Pinto, Thomas and Inkson, Van Nispen and more)

- Cultural Differences between States D'Iribarne, Hofstede, Trompenaars, Mole, Solomon and Schell and more)

- Values and Beliefs

- Definitions (Halman, Wood, Brink)

- European Values Study

- World Values Study

- Shift to Post-modern Society

- Dealing with Cultural Differences

- Communication

- Communication across Cultures (Hoffman, Hall)

- Dealing with Cultural Differences (Thomas and Inkson, Trompenaars, Hall, Van Nispen)

All students had actual experience with living and working abroad but this could not get the attention it deserved during the lectures. For this reason students were asked to write an individual paper on culture. At the same time the paper replaced the classical learning-by-root exam (but still guaranteeing academic standards).

The objective of the papers was to 'force' students to reflect on the content of the introductions on culture in view of their own experiences. In order to do so the students were given two general questions as a starting point: what is culture to you? how do you deal with cultural differences?

The form of the paper was deliberately left open, because educational theory stresses that creativity and motivation are promoted by decreasing as much as possible formal requirements or procedures. True or false, these papers confirm this idea through the results of these papers. The form varied in every imaginable way (scientific article, essay, 'letter to parents', blog, video and more) and the content accordingly. However, nearly all papers showed a strong involvement and a high quality in terms of thinking about culture.

The quality of these papers was high, as confirmed by other scholars. An important aspect to note is that the students did not limit themselves to the theories presented but also discussed theories, models, concepts, and perceptions and so on by others (ranging from scholars to novelists). Next to a critical discussion of the 
introductions on culture, the students presented their own views and came up with their own models.

\section{Quotes and Booklets}

Because of the high quality of many of these papers, the publication of quite of few of them in whatever framework would have been desirable but proved to be impossible. Instead of publishing the papers themselves the most interesting quotes from these papers were presented in a yearly booklet (approximately 200 A5-size pages, private publications). These booklets had over the years the same form. At the core was a summary of the introductions on culture, up to $10 \%$ of the booklet. At each point of interest in this summary the relevant quotes were added. Summary and quotes were set in different fonts. This allowed the reader to focus either on content or on practice (the quotes). Because of a rather intensive use of headings, people could also read the combination of theory and practice on a specific topic. Reading from cover-to-cover was of course also an option.

From year to year the booklets slightly varied in structure, trying to find the optimum way for presenting the different quotes in terms of cohesiveness of content. This struggle in trying to square the cultural circle proved its value in the development of the mind-map on culture (see below).

The selection of the quotes has been consistent over the years. Firstly, the selection was done by one and the same person, the lecturer in question. This is of importance because everybody looks with different glasses to the world and hence, consistency in selection by different people would be difficult at best. Secondly, strictly private elements were not selected. Anonymity was key, also stressed by mentioning the names of all students in one table at the beginning of each booklet and the nationalities in question in a second table. Names in the quotes were shortened to their initials. Some students indicated that they did not want their papers included and this was of course respected. Thirdly, remarks that just repeated what had been said in class were not included; the content of the introductions was considered as given. In the same vein quotes from other researchers on culture were not included, unless the student gave them an original twist. What remained were quotes with original perceptions and extraordinary individual experiences, sometimes, the understanding of culture and stressing the richness and variety of the concept.

The nine booklets from 2005 till and including 2013 were well received, building pressure to do more with the content of these papers. From a scientific point of view an argument could be made for the quality of this information. Firstly, the sheer number of papers (849) gives a guarantee in itself, because outliers may easily be separated from the bulk of understanding. Secondly, the group in itself is consistent. All of them are master students, most of them in their early twenties and (near- 
ly) all of them with experience with living and studying or working abroad. Those experiences are spread over the globe (including places like Fiji, Réunion, Uganda and the Cayman Islands). In terms of nationality students came from 53 states and some had more than one nationality. Overall, nationalities favoured Western countries with Germany and the Netherlands in the lead.

\section{Further Research}

Again and again people came up with ideas and suggestions on how to do more with the collection of papers. Ultimately a project in between research and education was developed. The advantage of the material is its consistency (papers as a result of one and the same assignment, within similar educational programmes, written by students in the same age group and in comparable programmes, all at master level and with experience abroad), as well as the number of papers (849). This contrasts with research on the basis of national representative samples. Such a different starting point may well result in a different perception of culture.

The first question that needed answer was to get an idea of the topics discussed over the years. On the basis of the extensive tables of content (see above) of the nine booklets an overview was obtained. The original list contained both topics of content and topics referring to theories of researchers. A topic like 'Theory of Hofstede' was converted in four topics in accordance with Hofstede's original four dimensions. The list reflects an inductive perception of culture.

In order to create coherence between all topics a mind-map was developed (see below). The terms in the mind-map will later be hyperlinked to Word documents on the same topic. Each Word document will contain the quotes by students on the specific topic. In addition, the document may start with an official definition of the topic in question or reference to further research. Possibly the analysis of the quotes on a given topic may also indicate specific aspects of that topic.

Part of the topics mentioned referred to the culture of specific countries (over 50; again: experience, not necessarily representing the scores of comparative research). These quotes were also organised in Word documents. These documents also include the values by Hofstede, the values of Solomon and Schell, the response to some items of the World Values Survey and three aspects of the Global Entrepreneurship Monitor. Access to these Word documents is realised by a Powerpoint world map. People may click on a given country (or the name of that country in the second sheet) and see the quotes in question (the countries are hyperlinked to Word documents in Dropbox).

Ultimately the mind-map will be the basis of a serious game on obtaining the basis of the cultural competence. The basis of the game is a map of a country, divided into a hundred parts, each of them referring to an aspect of culture in accordance with the mind-map. One may click on one of these parts, see what aspect 
of culture it represents and then do an exercise on that topic. When the exercise has been completed, the theory on that aspect is presented. The menu offers different ways of going through all the exercises and theory, as well as a series of tests.

\section{Mind-map}

The development of a list of topics on culture into a consistent mind-map implies a series of choices and assumptions. They will be explained below. At the same time one needs to keep in mind that many topics of the mind-map are related to series of other topics. Below the surface of the mind-map one needs to recognise this spider web of mutual relations. The mind-map is the analytical perception of culture, the spider web the comprehensive one. If one focuses on the mind-map, one may recognise the elements of culture but miss out on how everything is entangled with one another. On the other hand, the focus on the spider web gives an idea of the whole but makes it difficult to recognise specific aspects.

Figure 1 shows the overall mind-map. This is clearly too complex to grasp as such and hence, it will be discussed block by block.

The mind-map simply starts by putting 'culture' in the middle. Then the key decision needs to make by choosing the main branches. Considerations on content join hands with assumptions and the question is to make those assumptions as explicit as possible. As mentioned above this process was made somewhat easier by the experience of the yearly struggle in structuring the booklets but this was not sufficient in itself.

The process started with 'research'. For two centuries people study culture (in different disciplines, in different ways with different results and different objectives). Hence, an overview of research on culture needs to included and because of its importance it should be on this first level. Research was often the basis of papers and sometimes research delineated perceptions of culture. At the same one needs to keep in mind that the theory and practice of culture are not always well aligned with another.

The research resulted in definitions (statements) and concepts (more detailed descriptions, models, visuals) of culture, the second main branch. Again, the list of definitions and concepts is not exhaustive and the creativity of students resulted more than once in other definitions and concepts. As an example we might mention the very useful concept of Richard D. Lewis. This was not included in the introductions because the actual data per country are commercially protected. However, some students did mention this work. Indeed, if one accepts the mind-map and wants to add to it, this concept could be well one of the first to be added.

Research showed aspects of culture, concepts or terms one needs to describe specific cultures (whether at the level of a state or the level of a team). The focus is on content and hence, the elements of perceptions of researchers may easily be recognised (see below). 
Figure 2: a mind-map of culture

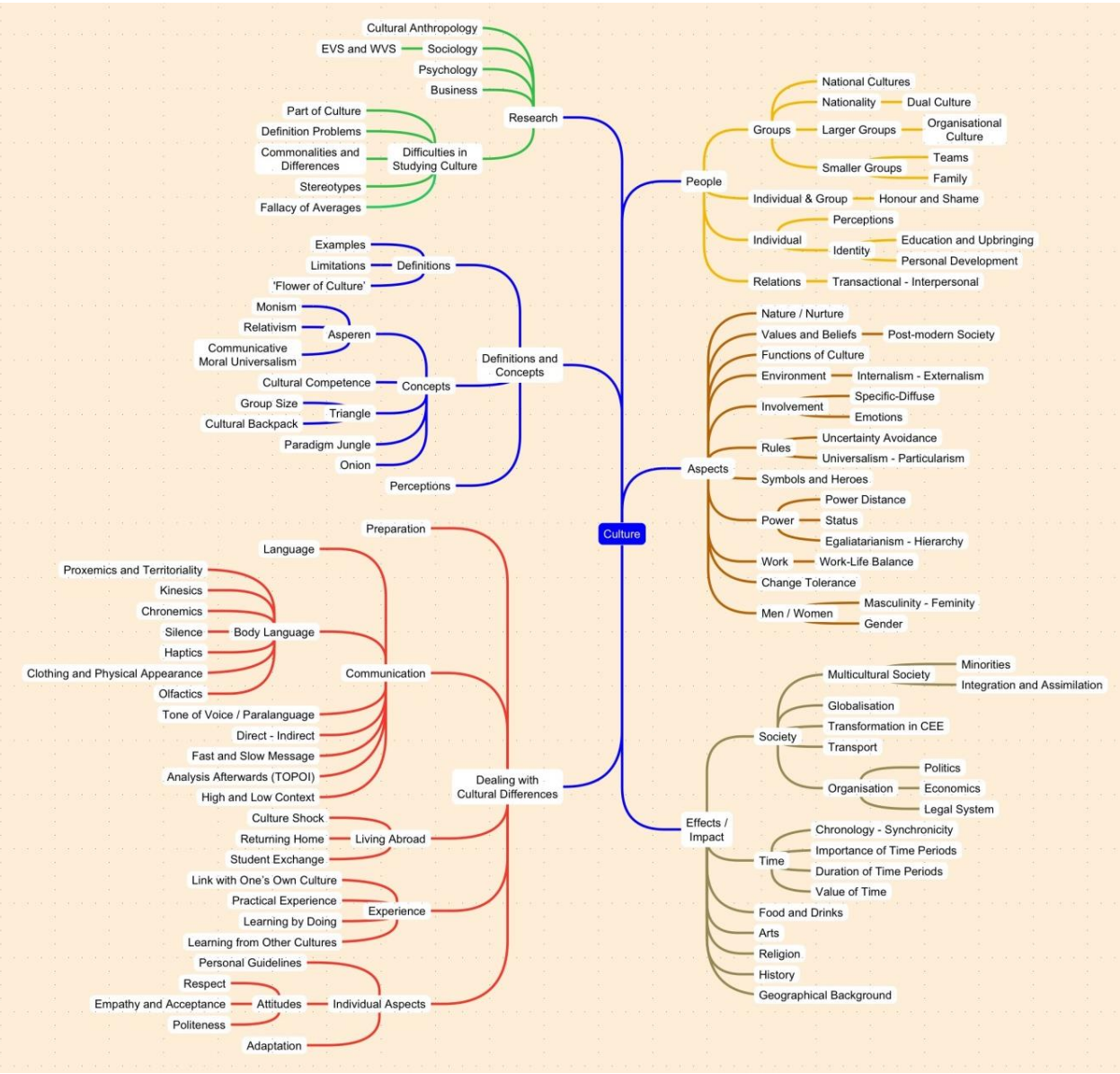

Figure 3: the six main branches of the mind-map

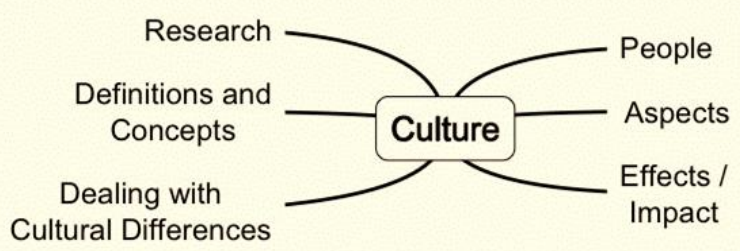

Next to 'aspects' one may recognise effects on culture. These effects are not necessary for describing a specific culture but rather show how culture affects the behaviour or thinking of people. Time for instance is not defined by culture but 
how we experience time actually is (from mañana to time is money).

The dichotomy of 'aspects' and 'effects' could have been sufficient to show what culture is in practice but proved to be not satisfactory. The reason is that culture is (mostly) a human 'thing', affecting the thinking and behaviour of individuals and the co-operation within groups. For this reason the human aspects were put together in the category 'people'.

Knowing about culture is one thing (from 'research' to 'people'), how to deal with differences in culture quite another. This consideration resulted in the final main branch, 'dealing with cultural differences'.

This division in the here mentioned six main branches drives of course the rest of the mind-map. At the same time one needs to recognise that this ordering might be logical for the one but not for the other. That's culture for you!

We will now discuss each main branch in some more detail. 'Research' has been divided in the four main scientific disciplines studying culture and five main barriers, hampering the study of culture (figure 4). The grouping of these five barriers is as such a result of the different papers and the opinions expressed therein.

Three specific points may be clarified. EVS and WVS stand for the European Values Study and the World Values Survey. The result of these academic endeavours may be found under 'aspects'.

The barrier 'part of culture' indicates that every individual is part of many different cultures and hence, can never be neutral in studying another culture.

The barrier 'fallacy of averages' refers to the methodology of the social sciences to work with representative groups and to calculate the average answer to specific questions. However, no single individual fully represents the calculated construct of the national culture.

Definitions and concepts (second main branch) also include 'perceptions'. In contrast to the more or less systematic or scientific approaches of culture individuals may have their own perceptions, for instance based on individual experiences.

Figure 4: the research branch of the mind-map

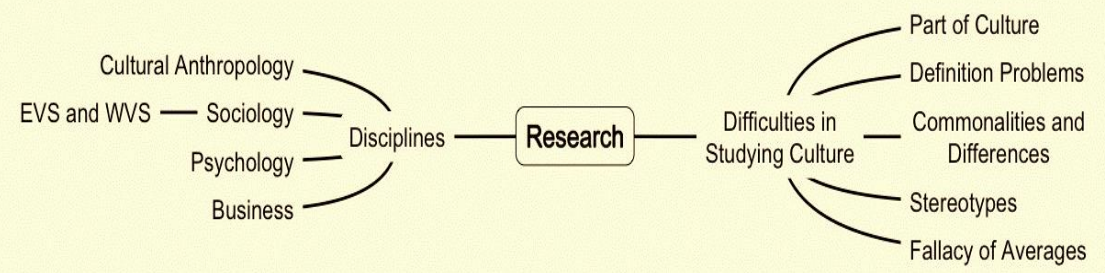

The 'flower of culture' (in category definitions) refers to one of the Powerpoint sheets used in the introductions and was named so by one of the students. The sheet indicates six overlapping circles, each circle representing one of the key aspects of 
culture (values and beliefs; thinking and acting; behaviour; groups; environment; time); figure 6 . These aspects may be considered as the most frequently mentioned aspects in hundreds of definitions of culture, although not one definition mentions them all. The student in question used 'flower of culture' to structure her paper, adding considerable value.

Figure 5: the definitions and concept branch of the mind-map

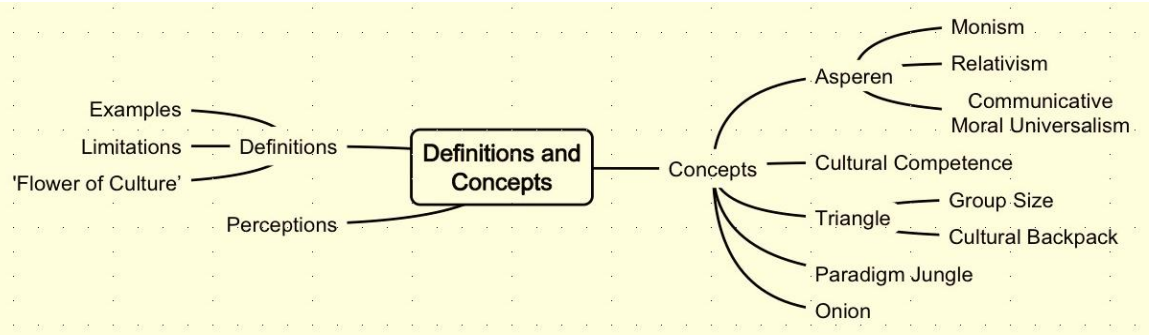

Researcher Van Asperen indicates on the basis of cultural anthropology three pre-conceived ideas of culture and although she puts them together in one model, it does not have an overall name.

Figure 6: Flower of Culture

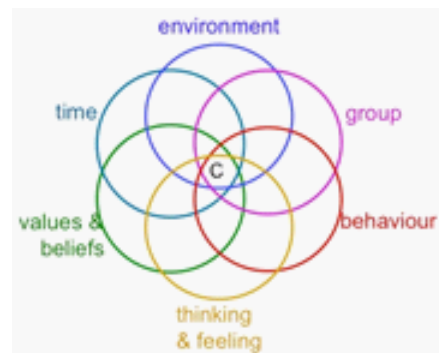

The concept Cultural Competence builds on the idea of Cultural Intelligence (CQ) by Thomas and Inkson. In the original form it refers to an integral combination of knowledge, adaptation of behaviour and mindfulness. In line with the Dutch competence based educational system this has been interpreted as an integral combination of knowledge, skills and attitudes.

The term 'paradigm jungle' refers to a remark by Baker in his book on paradigms. The idea behind is that each individual has been and is a member of dozens of different groups, ranging from the very specific (your own family) to the very abstract (all women in the Netherlands). Each group has its own culture in terms of preferred thinking, feeling and acting. Each culture is like a paradigm and each of us is shifting subconsciously all the time between these paradigms. 
Figure 7: the aspects branch of the mind-map

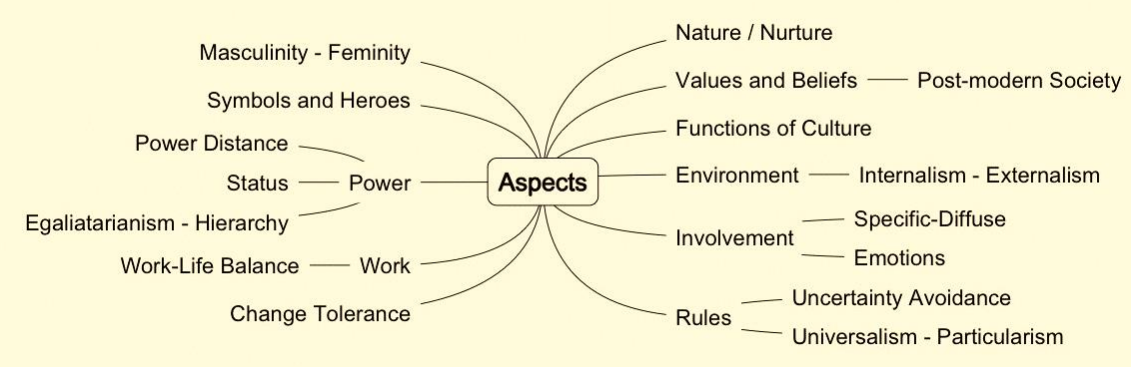

Research and definitions and concepts result in specific aspects, which we need to understand another culture to some degree (figure 7).

The term post-modern society refers to the theory of Inglehart that mankind is in the process of developing a fourth type of society (after hunters and gatherers, agricultural society and industrial society). The development was set $\mathrm{n}$ motion in the early seventies because the combination of health insurance, unemployment benefits and retirement funds decreased the importance of survival and allows for a new drive. The idea is that the Western world (at present) will put less emphasis on politics and hard work and more emphasis on the quality of existence and individual self-expression.

Symbols and heroes have been put together. Although some theories make a clear distinction between the two, one may also argue that heroes are symbols in a human form. Both are something to be proud of and both of them represent a larger value than itself / himself / herself.

Figure 8: the impact branch of the mind-map

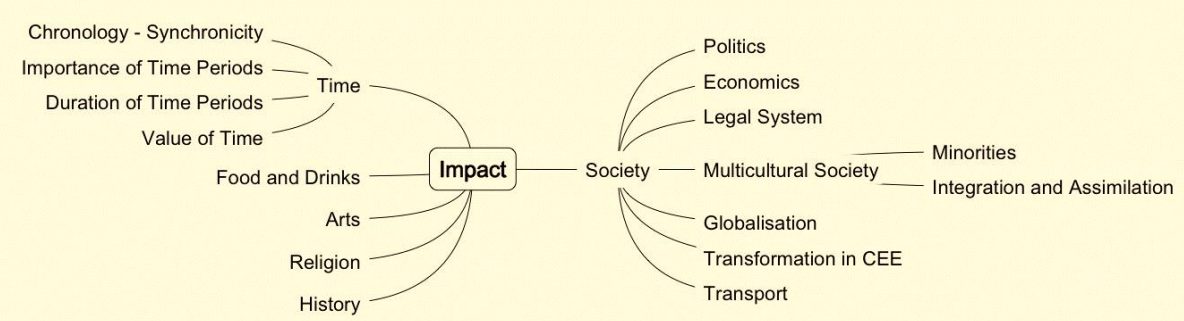


Figure 9: the people branch of the mind-map

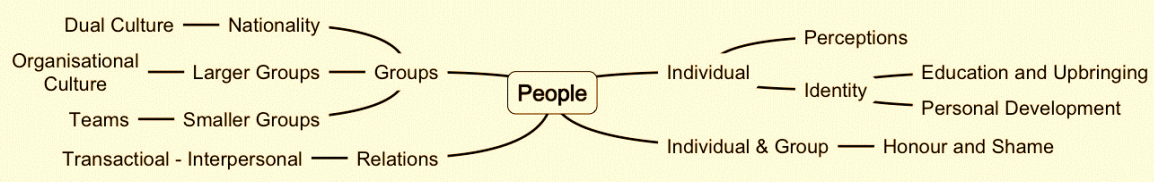

In the category 'society' the transformation in Central and Eastern Europe has been included. The point here is that the values studies learn that the shift in mentality from centralist and planned economy towards pluralist democracy and market oriented economy might well take three generations. The reason for such a long period is that people obtain values in their pre-adult years and that these values do not or hardly change afterwards. In addition one might say that the step is too big to be taken within one generation. However, individual people may move quite a bit faster. The three generations idea is based on the population at large (fallacy of averages!), including 'the small farmer out there'. This time aspect has also been recognised by people who fled Hungary in 1956 or Czechoslovakia in 1968.

Within the context of this mind-map people may be considered as the crossroads between aspects and effects. Figure 9 however, hardly contains new elements but rather represents another way of presenting the available information.

Finally then we would like to know how to deal with differences between cultures; the proof of the pudding (figure 10).

Figure 10: the dealing with differences branch of the mind-map

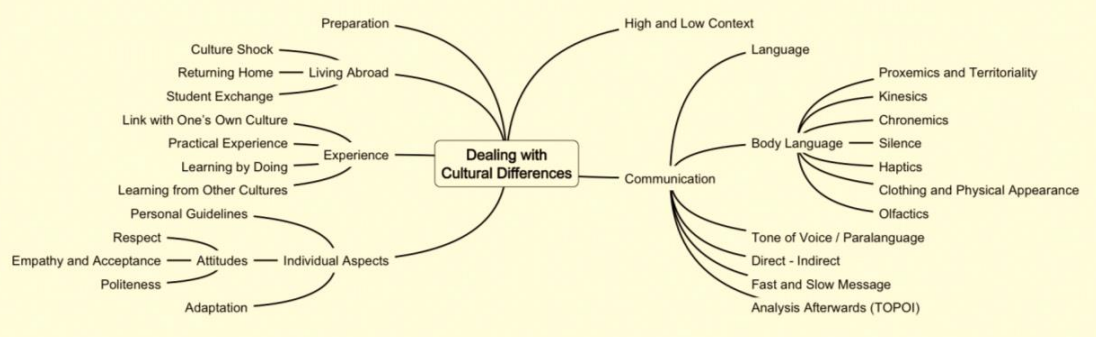

What we mostly see here is that people spend a lot of effort on getting on terms with this topic but that actual handles for dealing with cultural differences are scarce. This does not need to surprise you. From a theoretical point of view each individual is a unique combination of cultures and hence will always define the situation at hand different from any other person (however small). From a practical point of view more or less the same applies. Imagine yourself talking to another person in a situation of cultural differences. You react already to the other in terms 
of body language, something which cannot be fully controlled. Furthermore, you cannot delay your reaction by first reading a book on culture or following a training; you need to respond here and now.

\section{Conclusion and Continuation}

One may say that the mind-map, outlined in this paper is just the perception of a bunch of students. In view of the large number of students involved, their background and experiences, one may also argue that it would be hard to obtain a more comprehensive idea of what culture is. Following this second line of thought, more non-Western aspects should be included. In the same vein organisational culture might receive more attention but the academic value of the present research in that field is still subject to discussion. Furthermore, some aspects of living and working abroad have not been included, such as disadvantages of bilingualism, disengagement problems and dependency and isolation of spouse.

If one accepts the mind-map as an overall perception of culture, it may be used in training and education to orient people on the concept as a whole or to focus on a specific part. To do just that, the terms in the mind-map will be linked to documents with quotes on that topic and possibly some additional information. At the same time quotes on specific countries will be made available through a world map in Powerpoint.

Furthermore, the mind-map will function as the underlying grid in the development of a serious game on obtaining the cultural competence. This game may be played individually and off-line but may also be incorporated in programmes, like training and education but also for instance the preparation for an expat assignment abroad.

\section{Bibliography}

Asperen, E. van (2003) De relatie tussen visie, interactie en beleid; in Diversiteit werkt, Forum

Barker, J.A. (1996) Paradigma's, mentale modellen voor de toekomst, Scriptum Management (Dutch translation of Paradigms, The Business of Discovering the Future)

Brink, G. van den (2002) Mondiger of moeilijker? Een studie naar de politieke habitus van hedendaagse burgers, Sdu Uitgevers, 2002

European Values Study: http://www.europeanvaluesstudy.eu

Guirdham, M. (2005) Communicating across cultures at work, Palgrave Macmillan

Hall, E. en Hall, M. (1990) Understanding cultural differences

Halman, L. (2001) The European Values Study: A Third Wave. Source book of the 1999/2000 European Values Study Surveys, EVS, WORC, Tilburg University

Halman, L., Sieben, I. and Zundert, M. van (2012) Atlas of European Values, Trends and Traditions at the turn of the Century, Koninklijke Brill BV 
Hoffman, E.M. (1999) The TOPOI-model, A pluralistic systems-theoretical approach of intercultural communication (PhD thesis in Dutch with a summary in English)

Hofstede, G., Hofstede G.J. \& Minkov, M. (2010) Cultures and Organizations, Software of the Mind, Intercultural Cooperation and Its Importance for Survival, New York, McGraw-Hill

Inglehart, R. (1997) Modernization and Post Modernization, cultural, economic and political change in 43 societies, Princeton University Press

Iribarne, P. d' (1998) Eer, contract en consensus, Management en nationale tradities in Frankrijk, de Verenigde Staten en Nederland, Amsterdam, Uitgeverij Nieuwezijds (translation of La logique de l'honneur, published in 1989).

Lewis, R.D. (2006) When Cultures Collide, Leading across Cultures, Nicholas Brealey International

Mole, J. (1997) Zo doen we dat! over het omgaan en samenwerken met Europeanen, Academic Service; Dutch translation of Mind your Manners

Nispen, P. van (editor) (2006) Quotes 2005, private publication

Nispen, P. van (editor) (2007) Quotes on Culture 2006, private publication

Nispen, P. van (editor) (2008) Quotes on Culture 2007, private publication

Nispen, P. van (editor) (2009) Culture Experienced, Quotes 2008, private publication

Nispen, P. van (editor) (2010) Culture Experienced, Quotes 2009, private publication

Nispen, P. van (editor) (2011) Culture Experienced, Quotes 2010, private publication

Nispen, P. van (editor) (2012) Cultural Competence, Quotes 2011, private publication

Nispen, P. van (editor) (2014) Cultural Competence, Quotes 2012, private publication

Nispen, P. van (editor) (2014) Cultural Competence, Theory and Practice, Quotes 2013, private publication

Nispen, P. van \& Stralen, A. van (2009) Culturele Competentie, de verrijking door verschillen (Cultural Competence, enrichment through differences), Assen, Van Gorcum and accompanying website (www.culturelecompetentie.vangorcum.nl)

Pease, A. en Pease, B. (2004) The Definitive Book of Body Language, Orion

Pinto, D. (2004) Interculturele communicatie, conflicten en management, Bohn Stafleu Van Loghum

Solomon, Charlene M. and Schell, Michael S. (2009) Managing across Cultures, The Seven Keys to Doing Business with a Global Mindset, McGraw Hill

Thomas, D.C.and Inkson, K. (2004) Cultural Intelligence, People Skills for Global Business, Berrett-Koehler Publishers Inc.

Trompenaars, F., \& Hampden-Turner, C. (1997) Riding the Waves of Culture, understanding cultural Diversity in Business, Nicholas Brealey Publishing

Vroom, C. (2002) Kan het wel anders? Over de mogelijkheid van veranderen; in Nispen tot Pannerden, P. van, Vroom, C., Wagenaar, R. en Wouters, P. (redactie): Anders in verandering, Lemma

World Values Study: www.worldvaluessurvey.org 
Wood, J.D. (1997a) Culture is not enough, in: Mastering Management, Financial Times Pitman Publishing, p. 414

Wood, J. D. (1997b) The Nature of Ideology, in Mastering Management, Financial Times Pitman Publishing, p. 616 